\title{
Monitoring ovarian function and pregnancy in the giant panda (Ailuropoda melanoleuca) by evaluating urinary bioactive FSH and steroid metabolites
}

\author{
S. L. Monfort, K. D. Dahl*, N. M. Czekala†, L. Stevens, M. Bush and \\ D. E. Wildt
}

National Zoological Park, Smithsonian Institution, Washington, D.C. 20008, USA;

*Department of Medicine, Veterans Administration Medical Center, Seattle, WA 98108, USA; and $\dagger$ Research Department, Zoological Society of San Diego, San Diego, CA 92112, USA

\begin{abstract}
Summary. Urinary excretion of oestrone conjugates, pregnanediol-3 $\alpha$-glucuronide (PdG) and 20 $\alpha$-hydroxypregn-4-en-3-one were measured from 8 weeks before oestrus to 2 weeks post partum and bioactive FSH was monitored during the periovulatory interval in a female giant panda. A biphasic urinary bioactive FSH excretory profile appeared to indicate a broad ( $\sim 10$ day) follicular phase followed by a sharp preovulatory bioactive FSH surge coincident with an acute increase in urinary oestrone conjugates and behavioural oestrus. Weekly concentrations of urinary oestrone conjugates and PdG increased $(P<0.001)$ by Week 9 of gestation with $20 \alpha$-hydroxypregn-4-en3-one levels increasing 10-30-fold $(P<0.001)$ between Weeks 11 and 14 . These observations indicate that the monoestrous giant panda does not appear to require a prolonged period of endogenous FSH release or multiple FSH peaks for ovarian priming and follicle selection to proceed normally. Furthermore, the delayed rise in urinary steroid excretion during the second half of gestation in the giant panda supports the concept of delayed implantation while the estimation of steroid conjugates in urine offers a non-invasive approach for monitoring pregnancy status in this endangered species.
\end{abstract}

Keywords: giant panda; oestrogen; progesterone; FSH; delayed implantation

\section{Introduction}

The giant panda (Ailuropoda melanoleuca) once inhabited most of the mountainous bamboo forests in southeast China, but today the wild population (estimated at only 1000 individuals) is confined to 6 mountain preserves in the Gansu, Shaanxi and Sichuan provinces (Knight et al., 1985; Hoessle et al., 1988). Currently, about 80 giant pandas are maintained in captivity in China while 18 pandas are housed in zoological parks outside that country (Hoessle et al., 1988). Females are seasonally monoestrous with a single 2-3-day period of sexual receptivity usually occurring from March to May (Anon., 1974). Although more than 40 giant panda cubs have been born in captivity in China, few have survived to maturity. Because only 6 surviving offspring have been produced in western zoos since 1937, a more detailed understanding of the reproductive biology of this animal is required.

A gradually increasing database is being developed for this species, including the successful use of artificial breeding. Reports are available on the collection, analysis and freezing of giant panda semen (Platz et al., 1983) and 3 females have given birth after artificial insemination with fresh or thawed spermatozoa (Moore et al., 1984; Masui et al., 1988). Details of reproductive behaviour 
including courtship and mating patterns have been described (Kleiman et al., 1979; Kleiman, 1985). Bonney et al. (1982) reported increased urinary oestrogens in the female giant panda during the pro-oestrous interval while oestrogen concentrations declined during the period of sexual receptivity. In 1984, Hodges et al. confirmed ovulation and pregnancy in the giant panda by using non-invasive direct radioimmunoassay (RIA) of urinary steroidal metabolites. This work, which examined one complete pregnancy, suggested that the post-ovulatory rise in a progesterone metabolite (pregnanediol-3 $\alpha$-glucuronide, $\mathrm{PdG}$ ) was extremely attenuated, but by Week 12 after oestrus (75\% of gestation) PdG levels increased 4-fold above post-ovulatory concentrations, suggesting obligate delayed implantation. These observations were confirmed during pregnancy in Ling-Ling, the giant panda at the National Zoological Park (1984), while in 1985, a rise in urinary PdG levels 10 weeks after gonadotrophin-induced ovulation (with exogenous FSH-P) and mating with no subsequent birth provided circumstantial evidence that the species may experience pseudopregnancy (Chaudhuri et al., 1988).

To date, the endocrine events associated with the periovulatory interval, pseudopregnancy or pregnancy have been described by measuring only a single, or at most 2 , hormonal metabolites in samples often collected at sporadic intervals. The secretory patterns of gonadotrophins, including FSH associated with follicular/ovulatory activity, are unknown for the giant panda. Historically, the quantification of physiological FSH concentrations in biological fluids has been limited by the lack of sensitive and specific assay techniques. However, an in-vitro granulosa cell aromatase bioassay has now been described for measuring FSH in biological fluids (Jia \& Hsueh, 1985, 1986; Dahl et al., 1987b). In addition to measuring bioactive rather than immunoreactive FSH, this approach is non-species specific and already has been broadly applied to the human, gorilla (Gorilla gorilla), lion-tailed macaque (Macaca silenus), golden monkey (Rhinopithecus roxellana), giraffe (Giraffa camelopardalis), Asian elephant (Elaphas maximus) and killer whale (Orcinus orcus) (Dahl et al., 1987a, b; Walker et al., 1987).

In 1987, the giant panda Ling-Ling, at the age of 18 years, experienced a behaviourally normal oestrus, copulation, pregnancy and parturition. The opportunity to collect frequent urine samples provided a unique opportunity to detail and integrate retrospectively 3 urinary steroid metabolites and urinary bioactive FSH with known reproductive events.

\section{Materials and Methods}

Animals and sample collection. Housing and management of the giant pandas at the National Zoological Park have been described (Collins \& Page, 1973). Generally, Ling-Ling and the male giant panda Hsing-Hsing are maintained separately in indoor-outdoor enclosures within visual, aural and olfactory proximity. However, animals are permitted direct access to each other from $07: 00$ to 11:00 h on 3 days/week except during the breeding season when they are placed together on a daily basis. Behavioural signs indicative of onset of oestrus, including a marked increase in anogenital rubbing, vocalizations and scent marking, have been described in detail (Kleiman et al., 1979). Early morning urine samples were aspirated from the indoor, concrete enclosure floor and stored individually $\left(-20^{\circ} \mathrm{C}\right)$ without preservatives until assayed. Urine was analysed for creatinine $(\mathrm{Cr})$ content (Taussky, 1954) and all hormone values are expressed as mass units $/ \mathrm{mg} \mathrm{Cr}$. To eliminate urine samples which were diluted with extraneous water on the enclosure floor, samples containing $<0.1 \mathrm{mg} \mathrm{Cr} / \mathrm{ml}$ were discarded. This criterion resulted in the exclusion of 50 of 190 urine samples $(26 \cdot 3 \%)$.

Oestrone conjugates assay. Urinary oestrone conjugates were analysed with minor modification of the RIA procedures of Shideler et al. (1983). Unprocessed urine $(50 \mu \mathrm{l})$ was combined with $250 \mu \mathrm{l}$ Tris buffer at $\mathrm{pH} 8.4(0 \cdot 1 \mathrm{M}$-Tris, $0.9 \% \mathrm{NaCl}, 0 \cdot 1 \% \mathrm{NaN}_{3}, 0 \cdot 1 \%$ gelatin). Antiserum which cross-reacts equally with oestrone sulphate and oestrone glucuronide (anti-oestrone-3-glucuronide serum, $100 \mu \mathrm{l}, 1: 1500$; D. Collins, Emory University, Atlanta, GA, USA) and $\left[{ }^{3} \mathrm{H}\right]$ oestrone sulphate $(100 \mu \mathrm{l}, 7000$ c.p.m., sp. act. $55 \mathrm{Ci} / \mathrm{mmol}$ : Dupont-New England Nuclear, Wilmington, DE, USA) were combined with unknowns and standards (4.9-1250 pg/tube: Sigma Chemical Co., St Louis, MO, USA) and assayed in duplicate. After incubation for $1-3 \mathrm{~h}$ at $4^{\circ} \mathrm{C}, 300 \mu \mathrm{l}$ charcoal-dextran suspension $(0 \cdot 0625 \% \mathrm{charcoal}$, Norit A, $0.00625 \%$ dextran in $0.1 \mathrm{M}$-phosphate buffer, $\mathrm{pH} 7.0$ ) were added to separate antibody bound and free steroid. After a 30 -min incubation at $4^{\circ} \mathrm{C}$, tubes were centrifuged for $10 \mathrm{~min}$ at $1500 \mathrm{~g}$, decanted into scintillation vials, combined with $5.0 \mathrm{ml}$ Ready Solv HPb (Beckman Instruments Inc., Fullerton, CA, USA) and counted for $5 \mathrm{~min}$.

Serial dilutions of panda urine yielded displacement curves parallel to that obtained for oestrone sulphate standards. The mean ( \pm s.e.m.) recovery of oestrone sulphate (range, 4.9-1250 pg/tube) added to a pool of giant panda urine was 
$86 \cdot 3 \pm 4 \cdot 1 \%(y=0.91 x+6 \cdot 02, r=0.998, P<0 \cdot 0001)$. Assay sensitivity was $4.9 \mathrm{pg} /$ tube and inter-assay coefficients of variation for 2 separate internal controls were $7 \cdot 1 \%(n=5)$ and $12.4 \%(n=5)$, respectively, whereas intra-assay variation was $<5 \%(n=12)$.

Pregnanediol-3a-glucuronide assay. Urinary PdG was analysed using the methods of Mitchell et al. (1982) and Loskutoff et al. (1982) with the following modifications. Unprocessed urine samples often exhibited a high degree of non-specific binding which caused an underestimation of PdG mass. This problem was alleviated by pretreatment alcohol precipitation which involved combining undiluted urine $(100 \mu \mathrm{l})$ with $900 \mu \mathrm{l}$ absolute ethanol, vortexing for $1 \mathrm{~min}$ and centrifuging at $1500 \mathrm{~g}$ for $10 \mathrm{~min}$. Supernatants were decanted into test tubes, evaporated and reconstituted in $500 \mu$ phosphate buffer $(0 \cdot 1 \mathrm{M}, 0 \cdot 1 \%$ gelatin, $\mathrm{pH} 7)$. Mean $\left( \pm\right.$ s.e.m.) recovery of $\left[{ }^{3} \mathrm{H}\right] \mathrm{PdG}$ added to monitor procedural losses was $83.9 \pm 1.6 \%(n=10)$. Diluted urine $(50 \mu \mathrm{l}, 1: 5)$ was combined with $100 \mu$ l each of PdG antiserum $\left(\$ 02 /\right.$ zoo, 1:20000) and $\left[{ }^{3} \mathrm{H}\right] \mathrm{PdG}(7000 \mathrm{c.p} . \mathrm{m}$., sp. act. $42 \mathrm{Ci} / \mathrm{mmol}$ : both supplied by Courtauld Institute of Biochemistry, London, UK). The PdG antiserum cross-reacts $100 \%$ with PdG and $6.7 \%$ with pregnanediol. Urine samples and standards (19.5-5000 pg/tube: Sigma Chemical Co.) were incubated in duplicate overnight ( $\left.4^{\circ} \mathrm{C}\right)$. After the addition of $300 \mu \mathrm{l}$ charcoal dextran $(0.0625 \%$ charcoal, $0.00625 \%$ dextran), antibody bound and free steroid were separated with a $45-\mathrm{min}$ incubation at $4 \% \mathrm{C}$. After centrifugation $(1500 \mathrm{~g}$ for $10 \mathrm{~min})$, supernatants were decanted into scintillation vials and counted in $5.0 \mathrm{ml}$ Ready Solv- $\mathrm{HPb}$ for $5 \mathrm{~min}$.

Serial dilutions of panda urine yielded displacement curves parallel to that obtained with standard preparations. Recovery of known amounts of PdG (range, 39 to $2500 \mathrm{pg} /$ tube) added to a pool of diluted panda urine (50 $\mu \mathrm{l}, 1: 5$ ) gave a mean $( \pm$ s.e.m.) value of $99.5 \pm 1.6 \%(y=1.0 x-12.6, r=1.0, P<0.0001)$. Assay sensitivity was $19.5 \mathrm{pg} /$ tube and inter-assay coefficients of variation were $6.2 \%$ and $7.3 \%$ respectively, for 2 separate internal controls, and intra-assay variation was $<5 \%(n=10)$.

Assay of 20a-hydroxypregn-4-en-3-one. Urinary 20a-hydroxypregn-4-en-3-one was analysed using the method of Shideler et al. (1985) with minor modifications. A portion of urine $(10 \mu \mathrm{l})$ was pretreated with $900 \mu \mathrm{l}$ absolute ethanol similar to the pretreatment of PdG. Supernatants were evaporated and reconstituted in $300 \mu \mathrm{l}$ phosphate buffer $(0 \cdot 1 \mathrm{M}$, $0.1 \%$ gelatin, $\mathrm{pH} 7 \cdot 0)$. Antibody directed against $\mathrm{PdG}$-bovine serum albumin $(100 \mu \mathrm{l}, 1: 2000$ : provided by $\mathrm{S}$. Tillson, Syva Corp., Pailo Alto, CA, USA) was added to the sample with $\left[{ }^{3} \mathrm{H}\right] 20 \alpha$-hydroxypregn-4-en-3-one, $100 \mu 1 /$ tube, 7500 c.p.m., sp. act. $60 \mathrm{Ci} / \mathrm{mmol}$ : Dupont-New England Nuclear). The antiserum has the following cross-reactivities:

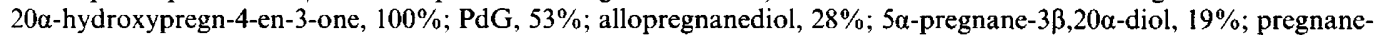
diol, $16 \% ; 20 \beta$-hydroxypregn-4-en-3-one, $1 \%$. Standards ranged from 31 to $5000 \mathrm{pg} /$ tube and incubation tubes were refrigerated $\left(4^{\circ} \mathrm{C}\right)$ for $24 \mathrm{~h}$ before $500 \mu \mathrm{l}$ charcoal-dextran separation of bound and free hormone.

The mean ( \pm s.e.m.) percentage recovery of unlabelled $20 \alpha$-hydroxypregn-4-en-3-one was $106.0 \pm 5 \cdot 3 \%$ (range, $10625 \mathrm{pg}$ ) and the regression equation was $y=1 \cdot 04 x-2 \cdot 15, r=1 \cdot 0$. Serial dilutions of a late pregnancy urine pool yielded a parallel dose-response curve. Inter- and intra-assay coefficients of variation were $18 \%$ and $14 \%$, respectively while assay sensitivity was $78 \mathrm{pg} / \mathrm{tube}$.

Granulosa cell aromatase bioassay. Bioactive FSH concentrations were measured using an in-vitro granulosa cell aromatase bioassay with modifications as previously described (Jia \& Hsueh, 1985, 1986; Dahl et al., 1987b). Granulosa cells obtained from immature Sprague-Dawley rats treated with diethylstilboestrol were cultured in 16$\mathrm{mm}, 24$-well culture plates. Each well contained $6 \times 10^{4}$ viable cells in $0.5 \mathrm{ml}$ McCoy's 5a medium (without serum, Gibco Laboratories, Santa Clara, CA, USA) supplemented with $2 \mathrm{mm-L-glutamine,} 100 \mathrm{U}$ penicillin/ml, $100 \mu \mathrm{g}$ streptomycin sulphate/ml, $10^{-6} \mathrm{M}$-androstenedione (Sigma), $10^{-7} \mathrm{M}$-diethylstilboestrol (Sigma), 0.125 mM-1-methyl3-isobutyl xanthine (Sigma), $1 \mu \mathrm{g}$ insulin/ml (porcine, Dr R. E. Chance, Lilly Research Laboratories, Indianapolis,

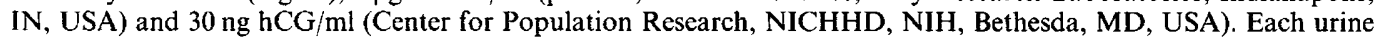
sample was assayed in triplicate at 3 dosage levels $(0 \cdot 1,0.2$ and $0.4 \mu \mathrm{l})$. A constant volume of urine $(0.4 \mu \mathrm{l} / \mathrm{culture})$ was maintained in all cultures (total volume, $500 \mu \mathrm{l}$ ) by the addition of gonadotrophin-free urine from oral contraceptive pill users. For standard curves, gonadotrophin-free urine $(0.4 \mu 1)$ was added to cultures containing increasing doses of a urinary gonadotrophin (Pergonal) preparation (Menotropins U.S.P., 7·5 i.u. FSH activity/mg, 7.5 i.u. LH activity/ mg; Second International Reference Preparation of human menopausal gonadotrophin: Serono Laboratories, Inc., Randolph, MA, USA) to correct for the effect of urine on the dose-response curve. At the end of the 3-day culture, medium was analysed for oestrogen content by RIA using an oestrogen antiserum (Dr Y. X. Liu, Institute of Zoology, Academia Sinica, China) as described previously (Jia \& Hsueh, 1985). The sensitivity of the granulosa cell aromatase bioassay was $0.06 \mathrm{mIU} /$ culture for Pergonal with inter- and intra-assay variations of $16 \%$ and $12 \%$, respectively.

High-pressure liquid chromatography. To determine the relative contributions of immunoreactive $\mathrm{PdG}$ and $20 \alpha-$ hydroxypregn-4-en-3-one excreted during late pregnancy, separate $50 \mu$ l portions of urine (at $13 \%$ and $83 \%$ gestation)

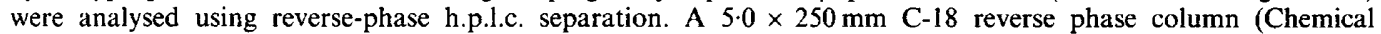
Engineering Co., Los Angeles, CA, USA) and a gradient flow of acetonitrile (Mallinckrodt, Paris, KY, USA) and water as solvent system were used as follows: $0-10 \mathrm{~min}, 40 \%$ acetonitrile; $10-20 \mathrm{~min}, 40-100 \%$ acetonitrile; 20-30 $\mathrm{min}, 100 \%$ acetonitrile. Flow rate was $1 \mathrm{ml} / \mathrm{min}$ and fractions were collected at $0 \cdot 2 \mathrm{~min}$ intervals. ${ }^{3} \mathrm{H}-\mathrm{labelled}$ PdG and 20a-hydroxypregn-4-en-3-one (2000 c.p.m.) were used as co-chromatographic markers to identify the elution profiles of the immunoreactive counterparts. Separate portions of column eluates were collected directly for counting of tracer and assayed for immunoreactivity using the 20a-hydroxypregn-4-en-3-one RIA described previously. 
Statistical analysis. Statistics were performed using SYSTAT (version 3.0, Wilkinson, 1987) on an Apple ${ }^{\circledR}$ Macintosh SE computer. Weekly mean hormone values reflect the mean \pm s.e.m. of individual early morning urine samples grouped in 1-week increments and aligned to the day of the bioactive FSH peak (Day 0). Statistical differences between PdG and 20a-hydroxypregn-4-en-3-one values before and after oestrus were determined using an independent samples $t$ test. Comparisons between grouped weekly mean hormone values were determined by one-way analysis of variance with individual hormone values transformed to natural logarithms before analysis to compensate for unequal variances.

\section{Results}

\section{Urinary bioactive FSH and oestrone conjugates}

The hormone values from 8 weeks before oestrus to 2 weeks post partum are presented in Fig. 1 . Ling-Ling exhibited overt behavioural oestrus and copulated 7 times over a 48 -h interval, onset coincident with Day 0. The duration of gestation (the interval from Day 0 until parturition onset) was 112 days. Analysis of urine samples over the interval from -20 weeks to -8 weeks failed to demonstrate any increase in bioactive FSH above basal levels. Near the peri-oestrous interval, however, urinary bioactive FSH (Fig. 1a) was excreted in a biphasic fashion. Baseline concentrations of bioactive FSH (1-2 IU/mg Cr) gradually increased 4- to 5-fold (6-7 IU/mg Cr), forming a broad peak between -4 and -2 weeks, followed by a return to baseline before a sharp 4-day long surge and peak levels of $44.3 \mathrm{IU} / \mathrm{mg} \mathrm{Cr}$ (30-fold above baseline; Day 0). Mean urinary oestrone conjugates concentration remained low $(3 \cdot 1 \pm 1 \cdot 0 \mathrm{ng} / \mathrm{mg} \mathrm{Cr})$ during the 8-week interval preceding Day 0 (Fig. 1b). By Day -10 , oestrone conjugates began a consistent and gradual rise with the preovulatory peak concentration $(69 \cdot 7 \mathrm{ng} / \mathrm{mg} \mathrm{Cr}$; Day 0$)$ representing a 20 -fold increase over basal levels. The oestrone conjugates peak was followed by a precipitous decline to $4.6 \mathrm{ng} / \mathrm{mg} \mathrm{Cr}$ by Day 3 with daily concentrations thereafter ranging from 0.3 to $6.4 \mathrm{ng} / \mathrm{mg} \mathrm{Cr}$ throughout pregnancy. By 8 weeks after the peak of bioactive FSH, weekly mean oestrone conjugates concentration decreased $(P<0.05$ ) from $3.3 \pm 0.7 \mathrm{ng} / \mathrm{mg} \mathrm{Cr}$ (Week 1) to $1.0 \pm 0.3 \mathrm{ng} / \mathrm{mg} \mathrm{Cr}$ (Week 8). Mean weekly levels between Weeks 9 and 16 increased steadily and were greater $(P<0.001)$ than mean weekly levels between Weeks 1 and 8 , reaching peak pregnancy concentrations of $4.6 \pm 0.4 \mathrm{ng} / \mathrm{mg}$ $\mathrm{Cr}$ at 1 week before parturition (Fig. 2a). Mean concentrations subsequently decreased during the first 2 weeks post partum.

\section{Urinary progestagens}

During the 8-week interval before Day 0, urinary PdG concentrations averaged $7.9 \pm 1.0 \mathrm{ng} / \mathrm{mg}$ $\mathrm{Cr}(n=25)$. PdG values (Fig. 1c) fluctuated considerably on a daily basis but mean levels for the 4 weeks after presumed ovulation were approximately 2-fold greater than before Day 0 $(16.0 \pm 1.7 \mathrm{ng} / \mathrm{mg} \mathrm{Cr}, n=18, P<0.001)$. Week 8 represented an inflection point in the qualitative excretory profile of PdG with mean weekly concentrations increasing 4-fold $(20.6 \pm 3.1 \mathrm{ng} / \mathrm{mg} \mathrm{Cr}$; Week 8 ) to $80 \cdot 5 \pm 15 \cdot 5 \mathrm{ng} / \mathrm{mg} \mathrm{Cr}$ by Week 14 . Mean weekly PdG values for Weeks 9-16 were elevated $(P<0.001)$ compared to mean weekly excretion rates for Weeks $1-8$. Weekly PdG concentrations decreased during Week $15(56 \cdot 1 \pm 3 \cdot 9)$ and Week $16(55 \cdot 2 \pm 8 \cdot 7 \mathrm{ng} / \mathrm{mg} \mathrm{Cr})$ and less than $24 \mathrm{~h}$ before parturition, daily PdG concentration decreased from $77 \cdot 3$ to $8.7 \mathrm{ng} / \mathrm{mg} \mathrm{Cr}$. In general, PdG concentrations after parturition remained below $10 \mathrm{ng} / \mathrm{mg} \mathrm{Cr}$. A prominent 1-day spike to $37 \cdot 2 \mathrm{ng} / \mathrm{mg} \mathrm{Cr}$ was detected 8 days post partum.

Mean 20a-hydroxypregn-4-en-3-one concentration during the 8 weeks before Day 0 averaged $31 \cdot 1 \pm 3.3 \mathrm{ng} / \mathrm{mg} \mathrm{Cr}(n=28)$ with levels increasing $(P<0.02)$ to $45.8 \pm 4.9 \mathrm{ng} / \mathrm{mg} \mathrm{Cr}(n=20)$ during the 4 weeks immediately after ovulation. The excretory pattern of $20 \alpha$-hydroxypregn-4en-3-one remained unchanged through Week 10, but from Weeks 11 to $1420 \alpha$-hydroxypregn4-en-3-one levels increased 10-30-fold to a weekly peak of $544.0 \pm 293.3 \mathrm{ng} / \mathrm{mg} \mathrm{Cr}$ (peak daily concentration, $1654 \mathrm{ng} / \mathrm{mg} \mathrm{Cr}$ ). The 20a-hydroxypregn-4-en-3-one excretion rate declined markedly from 13 to 16 weeks and was at pre-oestrus concentrations by 1 week post partum. 

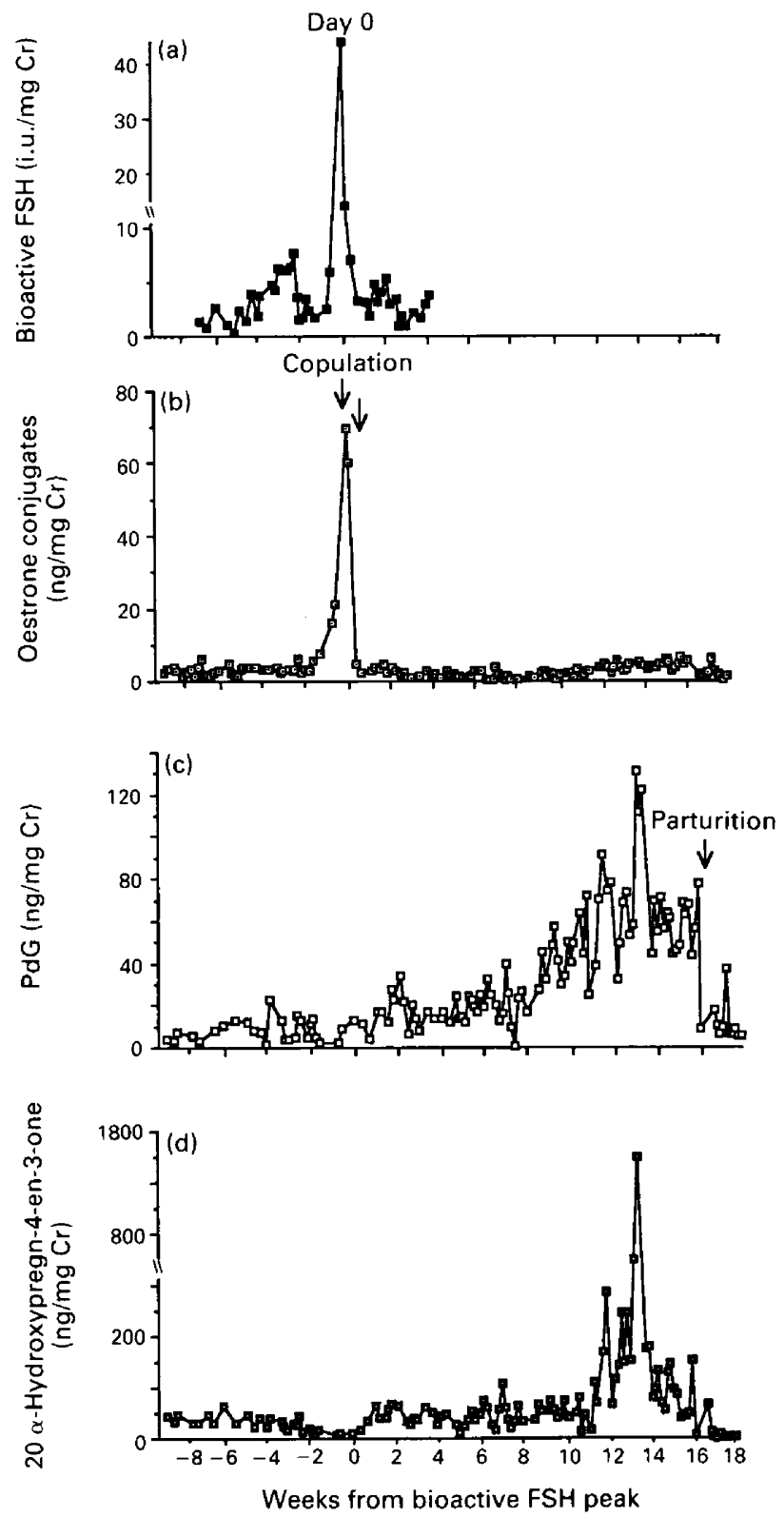

Fig. 1. Daily urinary bioactive FSH (a) and immunoreactive oestrone conjugates (b), PdG (c) and 20a-hydroxypregn-4-en-3-one (d) during the periovulatory interval and throughout gestation. Values are aligned to the day of peak bioactive FSH concentration (Day 0). Arrows denote days of copulation or parturition.

Although 20a-hydroxypregn-4-en-3-one immunoreactivity during late pregnancy was quantitatively greater than $P d G$, reflecting cross-reactivity with PdG and at least 4 other progestagen metabolites (see Fig. 3), the relative PdG immunoreactive profile appeared to provide an earlier indication of potential pregnancy as indicated by an earlier increase in metabolite excretion (Fig. 2b). 


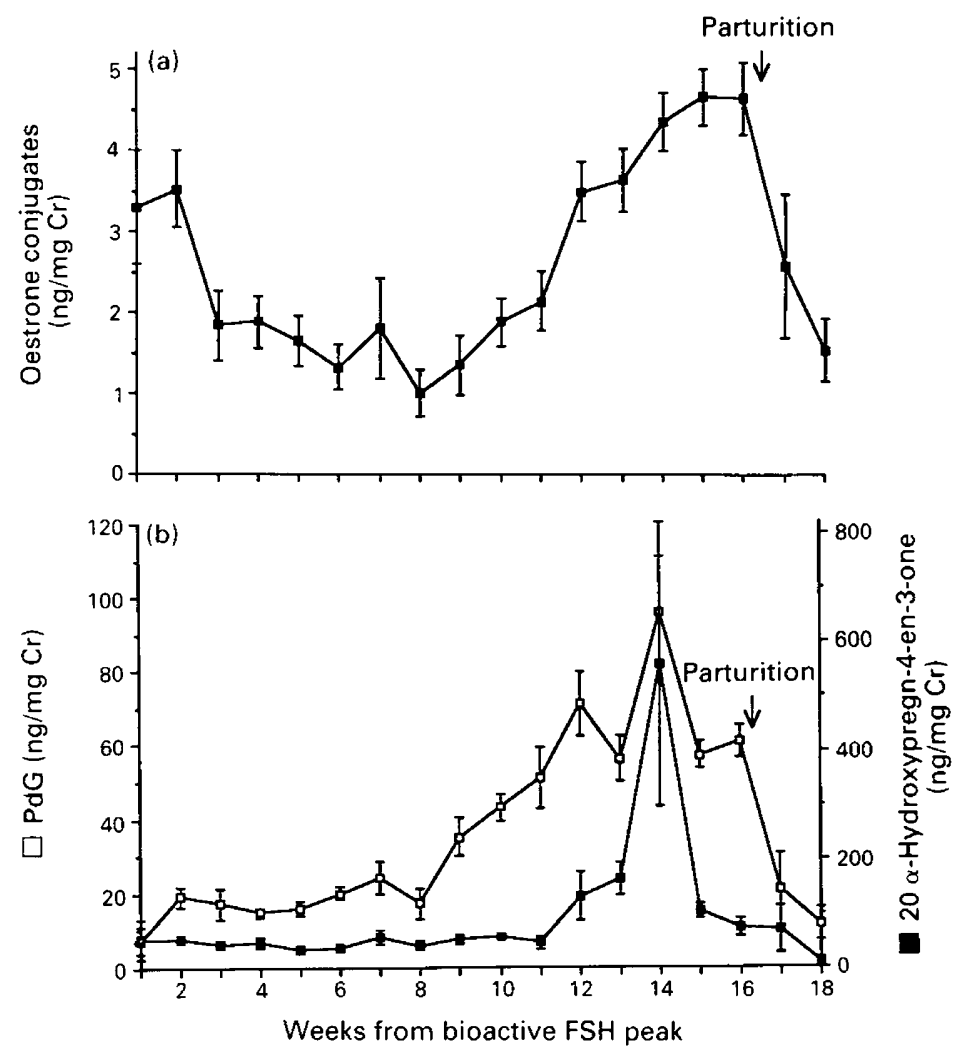

Fig. 2. Mean ( \pm s.e.m.) weekly immunoreactive urinary oestrone conjugates (a) and PdG, 20ahydroxypregn-4-en-3-one (b) from the week after the bioactive FSH peak until 2 weeks post partum. Values are aligned by the day of the bioactive FSH peak and the arrow indicates day of parturition.

\section{Co-chromatographic separation of progestagen metabolites}

The h.p.l.c. co-chromatographic profiles of 20a-hydroxypregn-4-en-3-one cross-reactivity obtained from early and late pregnancy urines (13\% and $83 \%$ of gestation, respectively) are presented in Fig. 3(a,b). Although the qualitative chromatographic profiles were similar in the 2 samples, total immunoreactivity was markedly increased during late gestation. At $13 \%$ of gestation, peaks co-eluting with $\left[{ }^{3} \mathrm{H}\right] \mathrm{PdG}$ (Fractions 6-14) and $\left[{ }^{3} \mathrm{H}\right] 20 \alpha$-hydroxypregn-4-en-3-one (Fractions 66-72) were the 2 predominant immunoreactive components; however, less prominent immunoreactive peaks were observed in the area of $20 \alpha$-hydroxypregn-4-en-3-one (Fractions $60-65 ; 72-90$ ). By $83 \%$ of gestation, PdG remained a major contributor to the overall immunoreactive profile whereas the relative contribution of $20 \alpha$-hydroxypregn-4-en-3-one was attenuated in relation to 3 unidentified immunoreactive peaks (Fractions 70-90). Furthermore, an additional, small unidentified, immunoreactive peak (Fractions 29-33), not observed at $13 \%$ of gestation, was present by $83 \%$ of gestation.

\section{Discussion}

This study integrates urinary hormone excretion in a giant panda which was sampled frequently during the periovulatory and pregnancy interval. Although the precise chemical nature of urinary 


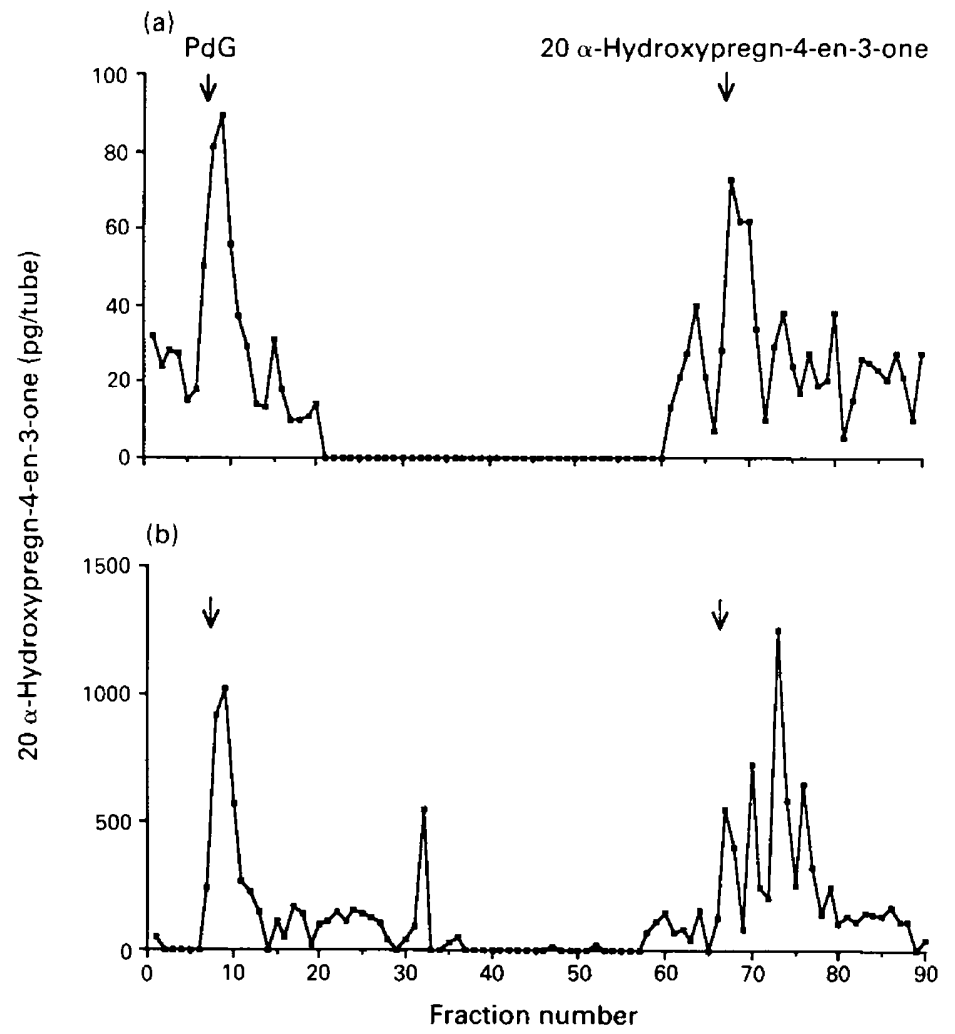

Fig. 3. Chromatographs of urine samples from $13 \%$ (a) and $83 \%$ (b) of gestation separated using reverse-phase h.p.l.c. Arrows indicate peak elution of $\left[{ }^{3} \mathrm{H}\right] \mathrm{PdG}$ and $\left[{ }^{3} \mathrm{H}\right] 20 \alpha$-hydroxypregn-4-en3-one (2000 c.p.m.) which were added as co-chromatographic markers to each urine sample before chromatography.

bioactive FSH remains to be elucidated, these data, and results of previous studies (Jia \& Hsueh, 1985, 1986; Dahl et al., 1987a, b; Walker et al., 1987) suggest that early morning urinary bioactive FSH levels reflect serum bioactive FSH concentrations and may serve as a valuable index for estimating FSH secretory activity. The extreme sensitivity and lack of species specificity make this approach particularly appropriate for species, such as the giant panda, for which adequate RIAs are unavailable. The female in this report exhibited a biphasic urinary profile of bioactive FSH consisting of a single follicular-phase peak followed by a preovulatory surge. These temporal patterns were qualitatively similar to those reported for the human, lion-tailed macaque, giraffe and killer whale (Dahl et al., 1987a, b; Walker et al., 1987). In contrast, the follicular phase of other mammals, including the gorilla, golden monkey and Asian elephant, is associated with multiple bioactive FSH peaks suggesting that a species-specificity exists either in the mechanisms governing follicular development or FSH excretion. From a comparative perspective, the $\sim 10$-day broad follicular bioactive FSH profile of the giant panda was similar to that of other mammals exhibiting a single follicular-phase bioactive FSH peak (human, 8 days; lion-tailed macaque, 10 days; giraffe, 6 days; killer whale, 9 days). This suggests that monoestrous species, such as the giant panda, may not require a period of sustained endogenous FSH release or multiple FSH peaks (beyond that observed in other polyoestrous species) for ovarian priming and follicle selection to proceed after prolonged ovarian inactivity. An expanding database detailing bioactive FSH secretory patterns in conjunction with steroid metabolites may lead to improved ovulation induction regimens and fertility diagnoses in the giant panda. 
The periovulatory excretory profiles for oestrone conjugates reported here were similar to previous reports for the giant panda (Bonney et al., 1982; Hodges et al., 1984; Chaudhuri et al., 1988; Masui et al., 1988). Although 1 mating occurred on Day 0 , most copulations $(n=6)$ occurred on Day 1 or on the descending limb of the oestrone conjugates surge. The bioactive FSH and oestrone conjugates peaks were detected coincidentally on the same day, as has been observed previously in other mammals (Dahl et al., 1987b). The seemingly late peak of oestrone conjugates probably reflects overproduction of hormone beyond the threshold stimulatory levels required for the events leading to ovulation.

In general, we observed a qualitatively similar PdG excretion profile to that reported earlier for this species (Hodges et al., 1984; Chaudhuri et al., 1988; Masui et al., 1988). Hodges et al. (1984) observed no substantial increase in PdG until 120 days after ovulation while Chaudhuri et al. (1988) reported increased PdG excretion immediately following ovulation. Our results indicate that mean weekly PdG and 20 $\alpha$-hydroxypregn-4-en-3-one excretion increased significantly during the 30-day interval after oestrus, demonstrating that the giant panda does exhibit a discernible lutealphase increase in progestagen metabolite excretion. Hodges et al. (1984) additionally suggested that giant pandas may undergo an obligate delay of implantation, similar to that observed in the European badger (Bonnin et al., 1978), western spotted skunk (Mead \& Eik-Nes, 1969a, b; Foresman \& Mead, 1974; Foresman et al., 1974), mink (Cochrane \& Shackelford, 1962; Møller, 1973), roe deer (Short \& Hay, 1966; Aitken, 1974) and black bear (Foresman \& Daniel, 1983). In these animals, soon after conception, embryonic development is arrested at the blastocyst stage followed by a variable period of embryonic diapause (Wimsatt, 1963). The arrested embryo is induced to attach physically to the uterine endometrium by an unknown signal which triggers a resumption of metabolic activity (Gulyas \& Daniel, 1967). Although evidence that the giant panda exhibits delayed implantation is circumstantial, the variable gestation length for the species (95-178 days) combined with the immaturity and low birthweight of newborn cubs are consistent with an abbreviated period of fetal development (Hodges et al., 1984). Additionally, abrupt acceleration in PdG and 20a-hydroxypregn-4-en-3-one excretion long after ovulation suggests that maternal ovaries or newly formed placental tissues are responding to an unknown stimulus from the implanting embryo. Similarly, the late gestational rise in the oestrogen metabolite may reflect placental production and/or fetal-maternal biosynthesis. Although the preimplantation interval appears quite variable in duration, post-implantational fetal development seems to be relatively fixed, terminating in parturition 4-6 weeks after an increase in the excretion of progestagen metabolites.

The assay for 20a-hydroxypregn-4-en-3-one clearly detects a variety of progesterone metabolites and represents a cumulative measurement of several progestagens. Although these data reflect only a single animal and should be interpreted with caution, this broad-spectrum antiserum is useful for identifying other potentially important progestagens excreted during pregnancy in the giant panda. Comparison of h.p.l.c. co-chromatographs from early and late gestation suggests that, in addition to PdG and 20 $\alpha$-hydroxypregn-4-en-3-one, at least 4 other progestagens are excreted during late pregnancy. Even though further work is required to elucidate the precise nature of these metabolites, their presence may indicate a post-implantational increase in fetal and/or fetalplacental-maternal steroid biosynthesis or may reflect an increase in the metabolic by-products of PdG or 20a-hydroxypregn-4-en-3-one. In either case, the 10-fold greater immunoreactivity of 20a-hydroxypregn-4-en-3-one observed during late pregnancy can be attributed to the increased excretion of these 'other' progestagens which cross-react with the $20 \alpha$-hydroxypregn-4-en-3-one assay.

From a practical perspective, the short interval required to conduct the laboratory analyses of oestrone conjugates and PdG allowed us to test the usefulness of these techniques for daily reproductive management. For example, the close relationship between the oestrone conjugates surge and copulatory behaviour permitted identification of the optimal interval for animal pairing. Since the antagonism between the National Zoo's male and female giant panda increases when the female 
is no longer sexually receptive, daily measures of activity of oestrone conjugates assist in confirming the termination of oestrus, thus lessening the chance of animal injury. The marked decline in PdG to baseline levels coincident with parturition also indicated that this procedure was useful for predicting birth, thereby facilitating the mobilization of personnel needed. The efficient estimation of impending parturition, however, necessitates that PdG values be monitored on a daily basis.

The question of pseudopregnancy in giant pandas remains unresolved. To our knowledge, 8 longitudinal urinary steroid profiles have been described in 4 giant pandas housed at different institutions (4 in Washington, 1 in London, 1 in Madrid, and 2 in Tokyo). In each case, PdG concentrations eventually increased after ovulation regardless of pregnancy status. Of the 8 profiles, 6 reflected known pregnancies. Of the remaining 2 profiles, 1 was from an animal experiencing endometrial hyperplasia (London) while the other occurred in Ling-Ling (Washington) even though no birth occurred (Chaudhuri et al., 1988). It is tempting to suggest that the giant panda may experience spontaneous pseudopregnancy which appears to serve as an autonomous mechanism for pregnancy protection in certain species in which the conceptus is perhaps a weak regulator of its own security during delayed implantation (Schams et al., 1980). Whether the unknown progestagens reported in this study can help distinguish between pregnancy and pseudopregnancy remains to be demonstrated. Until this question is answered, the differential diagnosis of pregnancy in this species remains equivocal.

We thank the keeper, veterinary and curatorial staff of the National Zoological Park for assistance in obtaining urine samples; Benjamin Beck of the National Zoo and Aaron Hsueh of the University of California, San Diego for support; and Janine Brown of the Uniformed Services University of the Health Sciences for helpful comments on the manuscript. The Endocrine Research Laboratory of the National Zoo is supported by grants from the Friends of the National Zoo (FONZ), Scholarly Studies Program of the Smithsonian Institution, the Women's Committee of the Smithsonian Associates, the Mars Foundation and the Center for New Opportunities in Animal Health Sciences (NOAHS Center).

\section{References}

Aitken, R.J. (1974) Delayed implantation in roe deer (Capreolus capreolus). J. Reprod. Fert. 39, 225-233.

Anon (1974) On the breeding of the giant panda and the development of its cubs, Peking Zoo. Acta zool. sin. 20, 139-147.

Bonney, R.C., Wood, D.J. \& Kleiman, D.G. (1982) Endocrine correlates of behavioural oestrus in the female giant panda (Ailuropoda melanoleuca) and associated hormonal changes in the male. J. Reprod. Fert. 64, 209-215.

Bonnin, M., Canivenc, R.M. \& Ribes, C.I. (1978) Plasma progesterone levels during delayed implantation in the European badger (Meles meles). J. Reprod. Fert. 52, 55-58.

Chaudhuri, M., Kleiman, D.G., Wildt, D.E., Bush, M., Frank, B. \& Thau, R.B. (1988) Urinary steroid concentrations during natural and gonadotrophininduced oestrus and pregnancy in the giant panda (Ailuropoda melanoleuca). J. Reprod. Fert. 84, 23-28.

Cochrane, R.L. \& Shackelford, R.M. (1962) Effects of exogenous estrogen alone and in combination with progesterone on pregnancy in the intact mink. $J$. Endocr. 25, 101-106.

Collins, L.R. \& Page, J.K. (1973) Ling-Ling and HsingHsing: Year of the Panda. Anchor Press, Doubleday, New York.
Dahl, K.D., Czekala, N.M. \& Hsueh, A.J.W. (1987a) Measurement of urinary bioactive follicle-stimulating hormone (FSH) levels during reproductive cycles in diverse mammalian species. Biol. Reprod., Suppl. 1, 36, 168, Abstr.

Dahl, K.D., Czekala, N.M., Lim, P. \& Hsueh, A.J.W. (1987b) Monitoring the menstrual cycle of humans and lowland gorillas based on urinary profiles of bioactive follicle-stimulating hormone and steroid metabolites. J. clin. Endocr. Metab. 64, 486493.

Foresman, K.R. \& Mead, R.A. (1974) Pattern of luteinizing hormone secretion during delayed implantation in the spotted skunk (Spilogale putorius latifrons). Biol. Reprod. 11, 475-480.

Foresman, K.R. \& Daniel, J.C. (1983) Plasma progesterone concentrations in pregnant and nonpregnant black bears (Ursus americanus). J. Reprod. Fert. 68 , 235-239.

Foresman, K.R., Reeves, J.J. \& Mead, R.A. (1974) Pituitary responsiveness to luteinizing hormone-releasing hormone during delayed implantation in the spotted skunk (Spilogale putorius latifrons); Validation of LH radioimmunoassay. Biol. Reprod. 11, 102-107.

Gulyas, B.J. \& Daniel, J.C. (1967) Oxygen consumption in diapausing blastocysts. J. cell. Physiol. 70, 33-36.

Hodges, J.K., Bevan, D.J., Celma, M., Hearn, J.P., 
Jones, D.M., Kleiman, D.G., Knight, J.A. \& Moore, H.D.M. (1984) Aspects of the reproductive endocrinology of the female giant panda (Ailuropoda melanoleuca) in captivity with special reference to the detection of ovulation and pregnancy. J. Zool., Lond. 203, 253-267.

Hoessle, C., Bruning, D., Kleiman, D., Foose, T. \& Schaller, G. (1988) Report of the Giant Panda Task Force, pp. 1-14. American Association of Zoological Parks and Aquariums. Wheeling, WV.

Jia, X.C. \& Hsueh, A.J.W. (1985) Sensitive in vitro bioassay for the measurement of serum follicle-stimulating hormone. Neuroendocrinology 41, 445-448.

Jia, X.C. \& Hsueh, A.J.W. (1986) Granulosa cell aromatase bioassay (GAB) for follicle-stimulating hormone: validation and application of the method. Endocrinology 119, 1570-1577.

Kleiman, D.G. (1985) Social and reproductive behavior of the giant panda (Ailuropoda melanoleuca). Bongo, Berlin 10, Proc. Int. Symp. Giant Panda, 45-58.

Kleiman, D.G., Karesh, W.B. \& Chu, P.R. (1979) Behavioural changes associated with oestrus in the giant panda (Ailuropoda melanoleuca) with comments on female proceptive behavior. Int. Zoo. Yb. 19, 217-223.

Knight, J.A., Bush, M., Celma, M., Garcia del Campo, A.L., Goltenboth, R., Hearn, J.P., Hodges, J.K., Jones, D.M., Klos, H.G., Monsalve, L., Montali, R. \& Moore, H.D.M. (1985) Veterinary aspects of reproduction in the giant panda (Ailuropoda melanoleuca). Bongo, Berlin 10, Proc. Int. Symp. Giant Panda, 93-126.

Loskutoff, N.M., Ott, J.E. \& Lasley, B.L. (1982) Urinary steroid evaluations to monitor ovarian function in exotic ungulates: I. Pregnanediol-3-glucuronide immunoreactivity in the okapi. Zoo Biol. 1, 45-53.

Masui, M., Hiramatsu, H., Nose, N., Nakazato, R., Sagawa, Y., Tajima, H. \& Saito, K. (1988) Reproduction by two artificial insemination of giant panda (Ailuropoda melanoleuca). Zoo Biol. (in press).

Mead, R.A. \& Eik-Nes, K.B. (1969a) Seasonal variation in plasma levels of progesterone in western forms of the spotted skunk. J. Reprod. Fert., Suppl. 6, $397-403$.

Mead, R.A. \& Eik-Nes, K.B. (1969b) Oestrogen levels in peripheral blood plasma of the spotted skunk. $J$. Reprod. Fert. 18, 351-353.

Mitchell, W.R., Presley, S., Czekala, N.M. \& Lasley, B.L. (1982) Urinary immunoreactive estrogen and pregnanediol-3-glucuronide during the normal menstrual cycle of the female lowland gorilla (Gorilla gorilla). Am. J. Primatol. 2, 167-175.

Møller, O.M. (1973) The progesterone concentrations in the peripheral plasma of the mink (Mustela vison) during pregnancy. J. Endocr. 56, 121-132.

Moore, H.D.M., Bush, M., Celma, M., Garcia, A.L., Hartman, T.D., Hearn, J.P., Hodges, J.K., Jones, D.M., Knight, J.A., Monsalve, L. \& Wildt, D.E. (1984) Artificial insemination in the giant panda (Ailuropoda melanoleuca). J. Zool., Lond. 203, 269-278.

Platz, C.C., Wildt, D.E., Howard, J.G. \& Bush, M. (1983) Electroejaculation and semen analysis and freezing in the giant panda (Ailuropoda melanoleuca). J. Reprod. Fert. 67, 9-12.

Schams, D., Barth, D. \& Karg, H. (1980) LH, FSH and progesterone concentrations in peripheral plasma of the female roe deer (Capreolus capreolus) during the rutting season. J. Reprod. Fert. 60, 109-114.

Shideler, S.E., Czekala, N.M., Kasman, L.H., Lindburg, D.G. \& Lasley, B.L. (1983) Monitoring ovulation and implantation in the lion-tailed macaque (Macaca silenus) through urinary estrone conjugate evaluations. Biol. Reprod. 29, 905-911.

Shideler, S.E., Mitchell, D.G., Lindberg, D.G. \& Lasley, B.L. (1985) Monitoring luteal function in the liontailed macaque (Macaca silenus) through urinary progesterone metabolite measurements. Zoo Biol. 4, 65-73.

Short, R.V. \& Hay, M.F. (1966) Delayed implantation in the roe deer Capreolus capreolus. Symp. zool. Soc. Lond. 15, 173-194.

Taussky, H.H. (1954) A microcolorimetric determination of creatine in urine by the Jaffe reaction. $J$. biol. Chem. 208, 853-861.

Walker, L.A., Czekala, N.M., Cornell, L.H., Joseph, B.E., Dahl, K.D. \& Lasley, B.L. (1987) Analysis of the ovarian cycle and pregnancy of the killer whale by urinary hormone measurement. Biol. Reprod. Suppl. 1, 36, 130, Abstr.

Wilkinson, L. (1987) SYSTAT: The System for Statistics. SYSTAT, Inc., Evanston.

Wimsatt, W.A. (1963) Delayed implantation in the Ursidae, with particular reference to the black bear (Ursus americanus Pallas). In Delayed Implantation, pp. 49-86. Ed. A. C. Enders. University of Chicago Press.

Received 23 May 1988 